\title{
Variations in the formation of supraclavicular brachial plexus among Kenyans
}

\author{
B.O. Olabu, BSc (Anat), J.A. Ogeng'o, BSc (Anat), MBChB, PhD, K.O. Awori, MBChB, MMed (Surg), \\ Dip. (SICOT), FCS (Orth), ECSA and H. Saidi, BSc (Anat), MBChB, MMed (Surg), FCS (ECSA) \\ Correspondence and reprint requests to: \\ B.O. Olabu, Department of Human Anatomy, University of Nairobi, P.O. Box 30197-00100, Nairobi, Kenya, \\ Email: bedaotn@yahoo.com
}

\section{Abstract}

OBJECTIVE: To describe the pattern and prevalence of variations that occur in the supraclavicular part of the brachial plexus in a Kenyan population.

STUDY DESIGN: Descriptive cross-sectional study.

MATERIALS AND METHODS: Ninety-four brachial plexuses from forty-seven formalin fixed cadavers were displayed by gross dissection.

RESULTS: The presence of at least one variation from the classical anatomy was observed in 73 $(77.7 \%)$ of the 94 plexuses. The roots and trunks were involved in $32(34 \%)$ of the plexuses . Preand postfixed roots were present in $23(24.7 \%)$ and $3(3.2 \%)$, respectively. The presence of four trunks, and trunks passing between the scalene medius and posterior were also noted. The long thoracic nerve was variant in 51 (54.3\%) of the plexuses. Unusual relations of the phrenic nerve to scalene muscles and the subclavian vein were encountered.

CONCLUSION: The presence of four trunks and an accessory phrenic nerve passing through the subclavian vein are probably described and reported for the first time. However, most of the variations of the BP among Kenyans are similar to those reported in the other populations.

\section{Introduction}

The complex anatomical organization of the brachial plexus predisposes its nerves to a wide range of variations throughout their courses (1-3). Variations of the supraclavicular brachial plexus involving the roots, trunks and their branches differ in prevalence among various populations. These include prefixation (4-7) and postfixation $(3,5,7)$. Variable relations of the plexus to the scalene muscles, absence or anomalous origin of some trunks and unusual communications have also been noted in some studies (3,8-11).

Apart from causing confusion in the assessment of upper limb nerve injuries, these anatomical variations can be responsible for failure of some brachial plexus nerve blocks or complications following these blocks $(3,6,9)$. Literature on the variations of the supraclavicular part of the brachial plexus among Africans is scanty and lacking in Kenyans. The present study describes the variations of the brachial plexus observed in a select Kenyan population.

\section{Materials and methods}

Ninety four brachial plexuses from 47 formalin fixed cadavers from both males and females used for routine dissection by first year medical students in the Department of Human Anatomy, 
University of Nairobi were displayed by gross dissection to study the supraclavicular brachial plexus. The posterior triangle of the neck was exposed by making skin incisions over the sternocleidomastoid muscle and the clavicle meeting at the insertion of the former, then turning the skin flap laterally. The investing layer of deep fascia of the neck was removed, the prevertebral fascia cleared and the trunks of the brachial plexus exposed and traced proximally to their origins in the cervical and thoracic spinal nerve roots.

The origins and courses of the long thoracic, dorsal scapular, suprascapular, and the phrenic nerves were defined. The relationships of the brachial plexus and these nerves (in the supraclavicular part) to the scalene muscles were photographed and recorded using a digital camera (Sony Cybershot ${ }^{\circledR}$ P200, 7.2 megapixels).

\section{Results}

\section{Roots}

Twenty three brachial plexuses $(24.5 \%)$ were prefixed while three $(3.2 \%)$ were postfixed (Figure 1). In one cadaver with bilateral cervical ribs, the roots on the left and right were prefixed.

\section{Table 1: Fixation of the brachial plexus}

\begin{tabular}{lcc} 
Fixation & No. & $(\%)$ \\
\hline No fixation & 68 & 72.3 \\
Prefixed & 23 & 24.5 \\
Postfixed & 3 & 3.2 \\
Totals & 94 & 100
\end{tabular}

\section{Trunks}

The presence of three trunks was observed in all except one case from the left side of a body where there were four trunks. In this case C8 root failed to unite with $\mathrm{T} 1$ root to form the lower trunk. These two roots were separated by the scalenus medius muscle, with T1 root running anterior to the muscle (Figure 2). The upper trunk was formed from $\mathrm{C} 5$ and $\mathrm{C} 6$ in 70 plexuses (74.5\%). Twenty three plexuses $(24.5 \%)$ had an additional contribution from $\mathrm{C} 4$ and were considered prefixed. In a single case of a postfixed plexus, the upper trunk was formed by the $C 5,6,7$ roots while the $\mathrm{C} 8$ root formed the middle trunk and the lower trunk from $\mathrm{T} 1,2$ (Figure 1). The C7 root continued as the middle trunk in 91 cases $(96.8 \%)$. In one subject with bilateral postfixation, the middle trunk formed from C7,8 (Figure 3). The lower trunk was formed by C8,T1 in 90 cases $(95.7 \%)$ and T1,2 in plexuses, where the latter were postfixed.

\section{Relation to scalene muscles}

For the upper roots, both $\mathrm{C} 5$ and $\mathrm{C} 6$ nerve roots passed within the scalene gap in 75 plexuses $(79.8 \%)$ and in front of scalenus anterior in three. The two roots were separated by scalenus anterior in 26 plexuses, in which C5 penetrated the muscle in most cases. Both the middle and lower trunks were found within the scalene gap in 92 plexuses (97.9\%). The middle trunk was between scalenus medius and posterior in 2 cases, either together with the lower trunk (1 case) or with the $\mathrm{C} 8$ root (1 case, Figure 2 ).

\section{Nerves}

Three modes of disposition of origin of the phrenic nerve were observed: (a) C3,4,5 roots in $61(64.9 \%)$ plexuses; (b) C4,5 in 2 cases; and (c) C3,4 in 31 cases. Of the latter group (31), 29 $(30.9 \%)$ had an accessory phrenic nerve. After its formation the phrenic nerve, in one case, lay lateral to the scalenus anterior (as opposed to anterior) and therefore it was not a content of the pyramidal space at the root of the neck. In the 29 plexuses $(30.9 \%)$ the accessory phrenic nerve had three modes of presentation at the roots : (a) 20 cases from the nerve to subclavius muscle; (b) 6 cases upper trunk; and (c) 3 cases C5 root. In relation to the subclavian vein, three courses were described. In 22 plexuses it passed anterior to the vessel and entered the thorax without joining the phrenic nerve within the neck. In the second course it was behind the vein in 6 cases and here the accessory phrenic nerve joined the phrenic nerve at the root of the neck. A modification of this was a 
communication between the two nerves before their final union observed in one case (Figure 4). The third route was observed in one case when an accessory phrenic nerve passed through the left subclavian vein (Figure 5).

The long thoracic nerve was formed from C5,6,7 roots in $69.1 \%, C 5,6$ in $28.7 \%$ and C6,7 in $2.1 \%$. All roots forming the nerve in either case passed through the scalenus medius in 41 cases

Figure 1: Left brachial plexus showing a postfixed type.

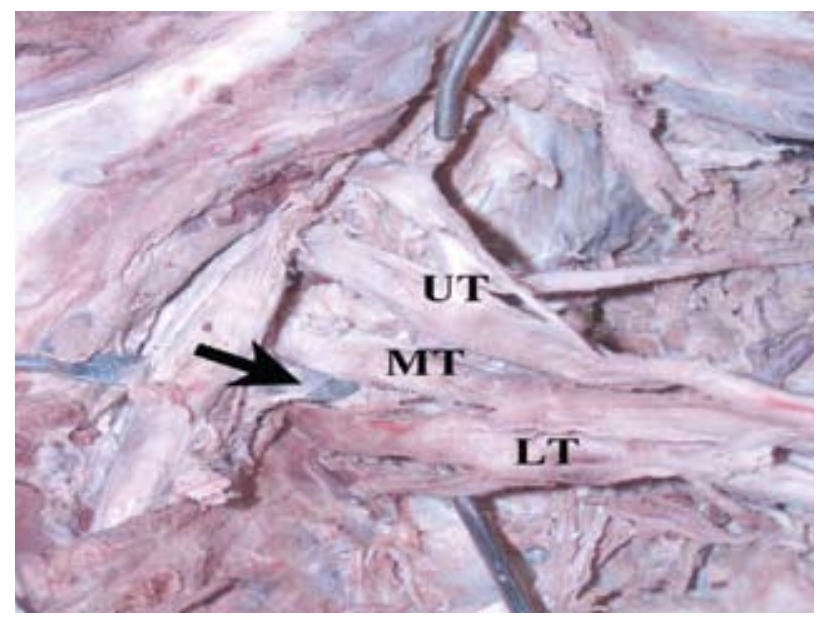

The upper trunk (UT) formed from C5,6,7 while the C8 root continued as the middle trunk (MT) and the T1,2 joined to form the lower trunk (LT) in this specimen. The arrow points at the $1 \mathrm{st}$ rib.

Figure 3: Left side of the neck showing a postfixed plexus

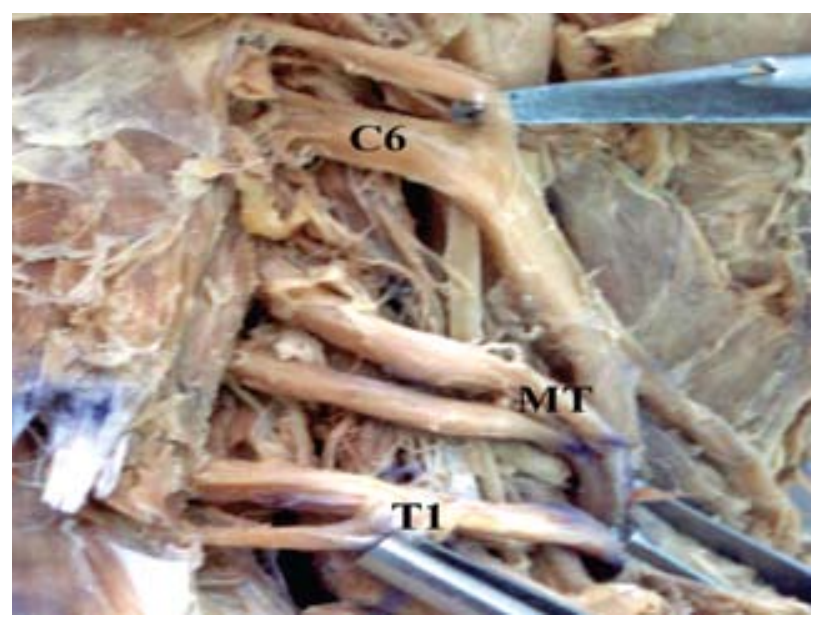

In this subject there was a bilateral postfixation, and the middle trunk (MT) formed from both $\mathrm{C} 7$ and $\mathrm{C} 8$ nerve roots.
$(43.6 \%)$ and within the scalene gap in 7 cases (7.4\%). In 43 cases the $C 7$ root passed within the scalene gap as the others pierced scalenus medius. The muscle was also traversed by the C5 root (2 cases) and C6 (one case) as the other nerve root(s) passed within the scalene gap. The classical textbook description of the origin and course of the long thoracic nerve within the neck was observed in $45.7 \%$ cases.

Figure 2: Left side of the neck showing a brachial plexus with four trunks because the $\mathrm{C} 8$ and $\mathrm{T} 1$ roots were separated by the scalenus medius muscle and so did not unite

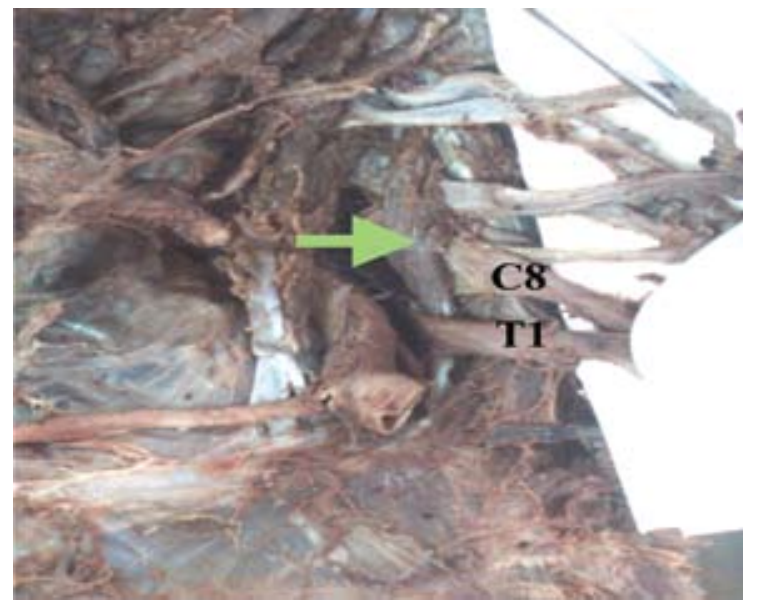

Note also the course of the middle trunk between scalenus medius (pointed) and posterior.

Figure 4: Left side of the neck showing an accessory phrenic nerve (thick arrow) taking a course posterior to the subclavian vein (SV). The nerve had a small communication with the phrenic nerve (thin arrow) proximal to their eventual union

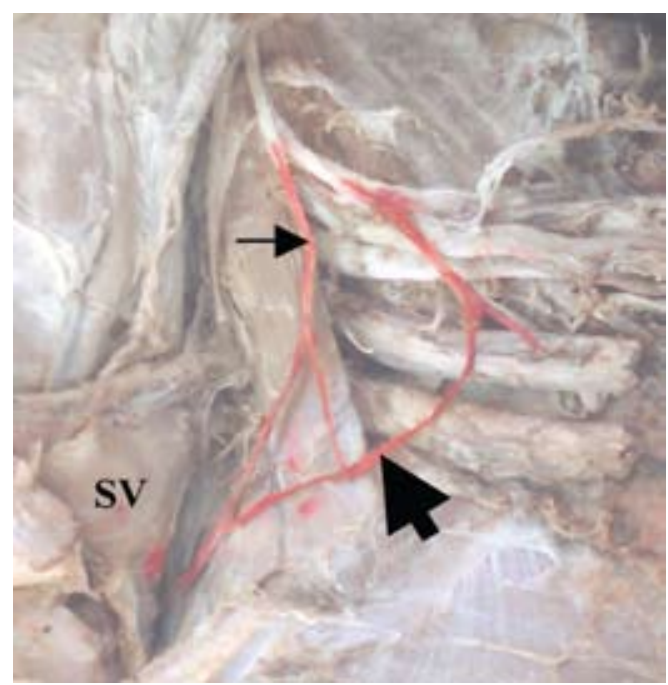


Figure 5: Left side of the neck showing an accessory phrenic nerve (small arrows) passing through the subclavian vein (SV). The anterior wall of the vein was cut to expose the nerve within the vessel. The APN then joined the phrenic nerve (big arrow) within the neck.

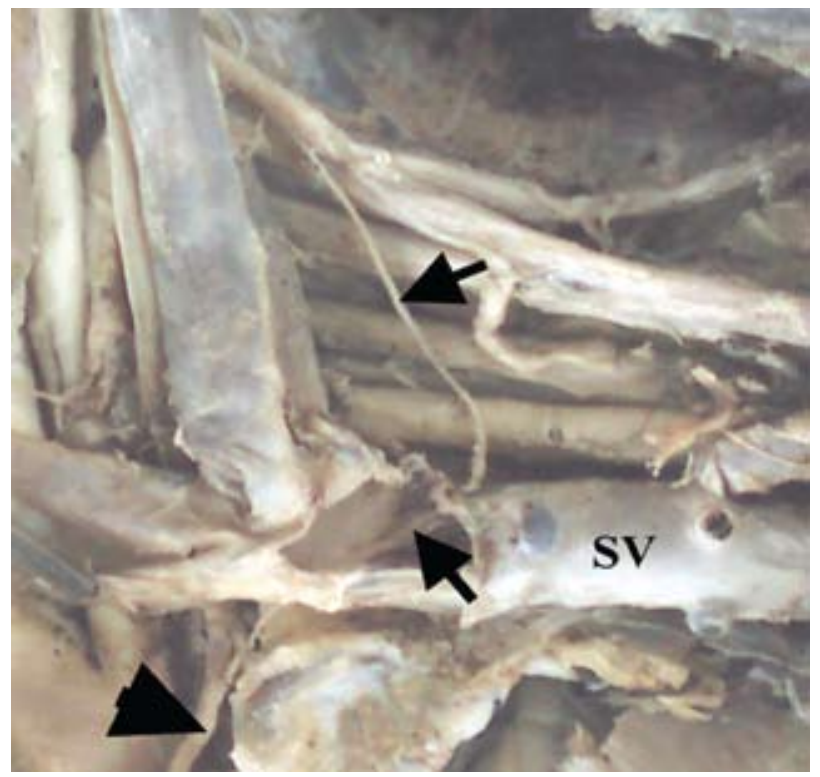

The suprascapular nerve originated from the upper trunk then curved towards the suprascapular notch with no variation to this classical pattern in all cases. Two variations of origin of the dorsal scapular nerve were reported: (a) from C5 root in 91 cases $(96.8 \%)$ and; (b) from $C 4,5$ in 3 cases. The nerve classically passed through scalenus medius in $80.4 \%$ plexuses and within the scalene gap in $19.6 \%$

\section{Discussion}

Observations of the present study have revealed an incidence of $27.7 \%$ in the variation of brachial plexus fixation, with prefixation being more common $(24.5 \%)$ than postfixation $(3.2 \%)$. These results are compared with those observed in various populations in Table 2.

The brachial plexus is considered prefixed when there is a large $\mathrm{C} 4$ root and the contribution from $\mathrm{T} 2$ being generally absent and that of $\mathrm{T} 1$ reduced. A postfixed plexus has a reduced or absent $\mathrm{C} 5$ but more dominant $\mathrm{T} 1$ and $\mathrm{T} 2$ contributions $(1,2)$. Apart from confusion in the assessment of upper limb nerve injury, a prefixation could possibly predispose the plexus to traction injuries involving the upper trunk or roots. A postfixed plexus on the other hand may increase the risk of injury to the T2 root by a cervical rib or any space occupying lesion like tumors of the apical lobe of the lung (1).

The usual three trunks were observed in $98.9 \%$ cases of the present study. Instances where $\mathrm{C} 8$ and $\mathrm{T} 1$ roots do not join but run as separate trunks, being separated by the scalenus medius muscle as observed in the present study are hitherto undescribed. Contribution of the C7 root to the upper trunk observed in one case confirms the findings of a previously reported case but unlike the present observation the middle trunk was absent in

Table 2: Incidence of brachial plexus fixation in various populations

\begin{tabular}{llcc}
\hline Author & Population or Country & \multicolumn{2}{c}{ Incidence (\%) } \\
\hline Ahmet and Sait, (5) & Turkey & 30.8 & 0 \\
Lee et al, (4) & Korea & 21.7 & - \\
Ongoiba et al, (6) & Mali & 30.4 & - \\
Matejcik, (7) & Slovenska & 48 & 2 \\
Uysal et al, (6) & Konya & 25.5 & 2.5 \\
Valéria et al, (3) & Brazil & 24 & 5.6 \\
Matejcik, (11) & Slovenska & 47.3 & 1.8 \\
Current study & Kenya & 24.5 & 3.2
\end{tabular}


the former case (12).

The finding that the middle trunk may be formed from $\mathrm{C} 7$ and $\mathrm{C} 8$ confirms the report of a previous study where a communicating branch from C8 (1 case) and lower trunk (1 case) joined the $C 7$ root (3). Such a middle trunk containing $\mathrm{C} 8$ fibres could be indicative of the musculocutaneous nerve receiving C8 contribution as suggested by Valéria and coleagues (3). If so, then a whole C8 root contributing to the formation of the middle trunk would therefore have a higher probability of giving rise to the nerves from the lateral cord, namely, the musculocutaneous and the lateral pectoral nerves. A variation of this type may have a potential to alter the myotome of either the elbow or shoulder flexors. Although connections between the nerves of the brachial plexus may provide alternative motor and sensory innervation following their lesions, they have been shown to cause confusion in the assessment of upper limb nerve injuries (9).

The study has shown that the brachial plexus roots and trunks lie between the scalenus anterior and scalenus medius (scalene gap) in $79.8 \%$ of the cases. Previous studies reported this to occur in $60-87 \%(8,13)$. As in these studies, the relation of the upper roots to the scalenus anterior muscle contributes to most of the variation. We have also shown probably for the first time the passage of the middle and lower trunks between middle and posterior scalene muscles. Such a variation may predispose an individual to the thoracic outlet syndrome (TOS), where the involved parts of the brachial plexus are entrapped within this intermuscular space (14).

Similar to previous studies, the $\mathrm{C} 4$ contribution to the phrenic nerve was consistent and therefore confirms its classification as belonging to the cervical plexus (1). The classical course of the nerve passing in front of scalenus anterior was seen in almost all cases (98.9\%). A phrenic nerve deviating from this course was seen in one case. In such aberrant course, the nerve may either be severed in surgical neck dissections or missed in phrenic nerve blocks $(14,15)$.

Previous studies on accessory phrenic nerve have reported a prevalence of $20-84 \%$
$(3,11,14,16)$. Our results of a prevalence of $30.9 \%$ is in conformity. The nerve is known to comprise mainly $\mathrm{C} 5$ fibres but may also be derived from the ventral rami of $\mathrm{C} 4$ or $\mathrm{C} 6$, or from the ansa cervicalis (1). The origin from the upper trunk may suggest contribution from both $\mathrm{C} 5$ and C6 ventral rami. With regard to its course, previous studies have observed it as passing either anterior or posterior to the subclavian vein. An accessory phrenic nerve passing through the subclavian vein is reported for the first time in this study. This course might constitute a potential hazard when carrying out a subclavian venepuncture.

The long thoracic nerve was formed by all the three roots $(C 5,6,7)$ in $69.1 \%$ of the cases, a finding that is relatively higher than what has been reported by other workers $(42-46 \%)(1,3)$. The course of the nerve through the scalenus medius was seen in $92.8 \%$, confirming similar findings of Valeria et al (3). The classical textbook description of the origin and course of the long thoracic nerve within the neck was observed in only $45.7 \%$ cases. There were no variations with regard to the suprascapular nerve. Although the variant origin of the dorsal scapular nerve was only from the $\mathrm{C} 4$ in the present study, this nerve may also receive contributions from $\mathrm{C} 4$ to T1 (4). Its main variations involved its course within the interscalene triangle. These variant courses of nerves may predispose them to injury during surgical dissections of the neck, or cause inadvertent nerve blockage or its failure. Nerves passing through muscles including long thoracic nerve, dorsal scapular nerve and roots of the brachial plexus have been long associated with entrapment syndromes when these muscles become hypertrophic or hyperactive. Such have also been described in pirifomic and pronator teres syndromes.

In conclusion, we report for the first time the presence of four trunks and an accessory phrenic nerve passing through the subclavian vein. These variations may be significant in evaluation of upper limb nerve injuries, application of nerve blocks and in surgical dissections of the neck. However, most of the variations of the brachial plexus described in this select Kenyan population are similar to those reported in 
the other populations. They involve pre- and postfixation of roots, the relations of the upper trunk to the scalenus anterior and those of the accessory phrenic nerve.

\section{References}

1. Williams P.L., Lawrence H.B., Martin M.B., et al. Nervous system: Gray's anatomy, Churchill Livingstone, London $38^{\text {th }}$ Edition. 1995; 1267-1274.

2. Romanes G.J. The peripheral nervous system. Cunningham's Textbook of Anatomy, Oxford University Press, London, New York, Toronto, $10^{\text {th }}$ Edition 1964; 725.

3. Valéria P.S.F., André de Souza A., Adilson L.C. et al. Brachial plexus variations in its formation and main branches. Acta. Cir. Bras. 2003; 18(5): 14-18.

4. Lee H.Y., Chung I.H., Sir W.S., et al. Variations of the ventral rami of the brachial plexus. J. Korean Med. Sci. 1992; 7(1): 19-24.

5. Ahmet $U$. and Sait B. Some variations in the formation of the brachial plexus in infants. Trop. J. Med. Scie. 1999; 29: 573-577.

6. Ongoiba N., Destriuex C, Koumare AK. Anatomical variations of the brachial plexus. Morpholo. 2002; 86(273): 31-34.

7. Matejcik V. Aberrant formation and clinical picture of brachial plexus from the point of view of a neurosurgeon. Bratisl. Lek. Listy. 2003; 104(10): 291-299.

8. Harry W.G., Bennett J.D. and Guha S.C. Scalene muscles and the brachial plexus: anatomical variations and their clinical significance. Clin. Anat. 1997; 10(4): 250-252.

9. Hoogbergen M.M. and Kauer J.M. An unusual ulnar nerve-median nerve communicating branch. J. Anat. 1992; 181: 513-516.

10. Uysal I.I., Seker M., Karabulut A.K., et al. Brachial plexus variations in human fetuses. Neorosurg. 2003; 53(3): 676-684.

11. Matejcik V. Variations of nerve roots of the brachial plexus. Bratisl. Lek. Listy. 2005; 106(1): 34-36.

12. Satheesha N., Nagabhooshana S., Venkata R.V., et al. A rare variation in the formation of the upper trunk of the brachial plexus - A case report. Neuroanatomy. 2005; 4: 37-38.

13. Natis K., Totlis T., Tsikaras P., et al. Variations of the course of the upper trunk of the brachial plexus and their clinical significance for the thoracic outlet syndrome: a study on 93 cadavers. Amer. Surg. 2006; 72(2): 188-192.

14. Bigeleisen P.E. Anatomical variations of the phrenic nerve and its clinical implication for supraclavicular block. Brit. J. Anaesthesia. 2003; 91(6): 916-917.

15. Abdelazeem Ali El-Dawlatly. Phrenic nerve paralysis after subclavian revascularization surgery: A case report. Internet J. Anesthesiol. 2004; 8: 1.

16. Okuda Y., Kitajima T. and Asai T. Use of a nerve stimulator for phrenic nerve block in treatment of hiccups. Anesthesiol. 1998; 88(2): 525-527.

17. Indrasingh I. and Vettivel S. A rare pseudo ansa cervicalis: A case report. J. Anat. Soc. India. 2000; 49(2): 178-179. 